\title{
Environmental modelling of NORM
}

\author{
R.S. O’Brien' ${ }^{1}$, P. McDonald ${ }^{2}$, C. Yu ${ }^{3}$, V. Koukouliou ${ }^{4}$, L.W. Setlow ${ }^{5}$, \\ J. Horyna ${ }^{6}$, D.P. Sanchéz ${ }^{7}$, T. al-Khayat ${ }^{8}$, P.W. Waggitt ${ }^{9}$, \\ G. Olyslaegers ${ }^{10}$, T. Zeevaert ${ }^{10}$, A. Canoba $^{11}$, V. Amado ${ }^{11}$ and K. Ivanova ${ }^{12}$ \\ ${ }^{1}$ ARPANSA, 619 Lower Plenty Road, Yallambie, 3085 Victoria, Australia \\ 2 Westlakes Scientific Consulting Ltd., The Princess Royal Building, Westlakes Science \\ and Technology Park, Moor Row, Cumbria CA24 3LN, UK \\ ${ }^{3}$ Argonne National Laboratory, 9700 South Cass Avenue, 60439 Argonne, Illinois, USA \\ ${ }^{4}$ Greek Atomic Energy Commission, Patriarxou Grigoriou \& Neapoleos, PO Box 60092, \\ 15310 Agia Paraskevi, Athens, Greece \\ ${ }^{5}$ U.S. Environmental Protection Agency (EPA), 1200 Pennsylvania Avenue, N.W., \\ 20460 Washington DC, USA \\ ${ }^{6}$ State Office for Nuclear Safety (SUJB), Senovazne Namesti 9, 11000 Prague 1, \\ Czech Republic \\ ${ }^{7}$ División de Protección Radiológia (Ed. 3, PI. 0, Des. 18), CIEMAT, Avenida COmplutense \\ 22, 28040 Madrid, Spain \\ ${ }^{8}$ Ministry of Science \& Technology (MOST), Al-Jadrya, PO Box 0765, Baghdad, Iraq \\ ${ }^{9}$ Waste Safety Division, Division of Radiation, Transport \& Waste Safety, IAEA, Vienna \\ Internationsal Centre, Wagramer Strasse 5, PO Box 100, 1400 Vienna, Austria \\ 10 Studiezentrum für Kernenergie (SCKICEN), Boeretang 200, 2400 Mol, Belgium \\ ${ }^{11}$ Autoridad Regulatoria Nuclear (ARN), Av. Del Libertador 8250, Capital Federal, \\ 1429 Buenos Aires, Argentina \\ 12 National Centre of Radiobiology and Radiation Protection, 132 St. Kliment Ochridski Blvd., \\ 1756 Sofia, Bulgaria
}

\begin{abstract}
Within the IAEA EMRAS programme, a working group was established to look at the modelling of naturally occurring radioactive material (NORM) in a variety of environments. There are many models already available. However, guidance on how and when to apply specific models is lacking in many cases. Development of models has often been carried out without a clear understanding of the possible applications of the models. Some models have been developed only for specific applications in specific industries, and are not generally useful. The work carried out during this program has resulted in the identification of several important issues that require consideration in the selection and utilization of computer models for NORM risk assessment. These issues discussed below cover suitability, selection, use and misuse of available models, as well as training and guidance for modelers, and acquisition of data for model inputs.
\end{abstract}

\section{INTRODUCTION}

Many currently available environmental assessment models have the capability to predict the transport and behaviour of individual radionuclides as a single contaminant. When dealing with NORM, due to the radionuclide decay schemes present, a wider variety of radiological and chemical behaviour needs to be accommodated within modelling packages. The aim of this work, which is part of the Environmental Modelling for Radiation Safety (EMRAS) program set up by the International Atomic Energy Agency, is to enhance capability for assessing the environmental impact of NORM residues and wastes (and legacy sites) by developing scenarios for testing models, evaluating existing models, and 
developing new models where possible. Details of the program, together with working group reports and meeting reports can be found on the Internet.

\section{MATERIALS AND METHODS}

\subsection{Hypothetical scenarios}

Three hypothetical scenarios have been developed, for a point source, an area source and an area source plus a river. The two area source scenarios assume ideal conditions, including simple geometry, homogeneity of the NORM residue, and uniform groundwater flow. Application of models to these scenarios has helped improve the scenario specifications and allowed comparison of the results from different models.

\subsubsection{Point source scenario}

This scenario is relatively simple, with a single stack $100 \mathrm{~m}$ in height, discharging ${ }^{222} \mathrm{Rn},{ }^{210} \mathrm{~Pb}$ and ${ }^{210} \mathrm{Po}$ at a specified rate. Wind-rose, atmospheric stability, and other environmental data are specified. Modellers were asked to calculate the annual doses to occupants of two houses at given locations and with given land use, occupancy and dietary data. This exercise was repeated three more times by rotating the wind rose details by $90^{\circ}$.

\subsubsection{Area source scenario}

The source in this case is a waste pile $1 \mathrm{~km}$ square, and $10 \mathrm{~m}$ thick, with a cover layer of $2 \mathrm{~m}$ of clean soil. The waste is underlain by a $3 \mathrm{~m}$ thick layer consisting of $80 \%$ sand and $20 \%$ clay, immediately above a $15 \mathrm{~m}$ thick aquifer. The direction and speed of groundwater flow in the aquifer are specified, together with other relevant environmental data. Modellers are asked to estimate the annual doses to the occupants of three houses, one above the waste and two others at different distances from the waste in the direction of groundwater flow. Occupancy, dietary and water usage (drinking, irrigation) data are also given. This exercise was repeated twice - modelling the scenario with and without the $2 \mathrm{~m}$ of clean soil.

\subsubsection{Area source + river scenario}

The source in this scenario is the same as for the area source, but a river $300 \mathrm{~m}$ from the down-gradient edge (with respect to groundwater flow) of the waste is included. Most of the data for this scenario are the same as the data for the area source scenario. River flow parameters and the positions of houses at different distances downstream form the waste are specified, and modellers are asked to estimate the annual doses to occupants of these houses.

\subsection{Real scenarios}

Development of real scenarios has proved difficult because of a lack of comprehensive data sets. However, four real scenarios have been examined, and are briefly described below.

\subsubsection{Camden}

This is a legacy site where a thorium processing facility and a gas mantle production facility were operated [1]. It is characterised by a highly heterogeneous distribution of contaminated material in a built up urban area near a large river. The available data indicate that there has been very little groundwater contamination even though there are several small creeks or streams in the area. This scenario has not been tested by the members of the working group. 


\subsubsection{Lignite power station}

This site consists of two power stations, situated close together, with a total of 5 stacks with a city approximately $5 \mathrm{~km}$ to the south east. Values of ${ }^{226} \mathrm{Ra},{ }^{232} \mathrm{Th}$ and ${ }^{238} \mathrm{U}$ concentrations in dust and on the ground surface have been measured, and meteorological (wind rose) data are also available.

\subsubsection{Phosphogypsum disposal - site 1}

This site is a series of connected deposition areas under a lake, very close to the coastline. A series of monitoring wells is used to collect data on ${ }^{226} \mathrm{Ra}$ concentrations in surface water and groundwater. The results of measurements of groundwater flow are also available.

\subsubsection{Phosphogypsum disposal - site 2}

This site is a single large phosphogypsum stack which sits on top of a deep layer of clay. A concrete wall has been built on the downstream side of the stack to restrict the flow of contaminants leached into the groundwater. Leachate is extracted from a series of wells along the downstream side of the stack and pumped back to the top of the stack. A series of monitoring wells is used to measure radionuclide concentrations.

\section{RESULTS AND CONCLUSIONS}

The hypothetical scenarios were tested by members of the working group. The results will be available in the working group final report [2]. The models used in this work are summarised in Table 1. Other models or modelling packages (for example AMBER) were described in the main report but not actually used by members of the working group for detailed testing of scenarios.

Table 1. The models used in this work, their type, and situations to which they were applied.

\begin{tabular}{|l|l|l|}
\hline Model & Type & Usage \\
\hline CROM [3] & Compliance & Point-source scenarios \\
\hline COMPLY [4] & Compliance & Point-source scenarios \\
\hline CAP-88 [5] & & \\
\hline PC-CREAM [6] & Detailed & Point source scenarios \\
\hline RESRAD v6. [7] & Detailed & Area source scenarios \\
\hline RESRAD-OFFSITE [8] & Detailed & $\begin{array}{l}\text { Area source scenarios } \\
\text { Area source + river }\end{array}$ \\
\hline DOSDIM + HYDRUS [9] & Detailed & Area source scenarios \\
\hline PRESTO v4.2 [10] & Simple & Area source scenarios \\
\hline
\end{tabular}

\subsection{Hypothetical point source}

Both simple and complex models were used for testing the point source hypothetical scenario. An example of the three models used in this study (CROM, COMPLY and PC-CREAM) is given in Figures 1 to 3 below. The dose values predicted by COMPLY over a 10000 year period range from approx $20 \mu \mathrm{Svy}^{-1}$ to $1 \mu \mathrm{Svy}^{-1}$; for CROM $9 \mu \mathrm{Sv} \mathrm{y}^{-1}$ to $0.3 \mu \mathrm{Sv} \mathrm{y}^{-1}$ and for PC-CREAM $6 \mu \mathrm{Sv} \mathrm{y}^{-1}$ to $0.5 \mu \mathrm{Sv}^{-1}$. In general, the dose values predicted by the simpler screening models were higher than those predicted by the complex model, PC-CREAM. However, reasonably good agreement of predicted values was achieved between CROM and PC-CREAM. 


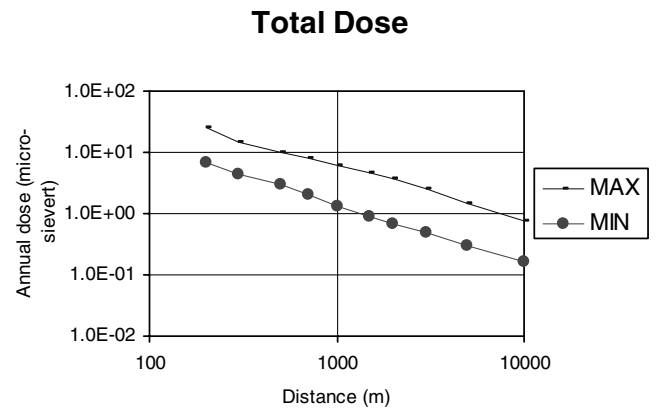

Figure 1. Hypothetical stack scenario - COMPLY predictions.

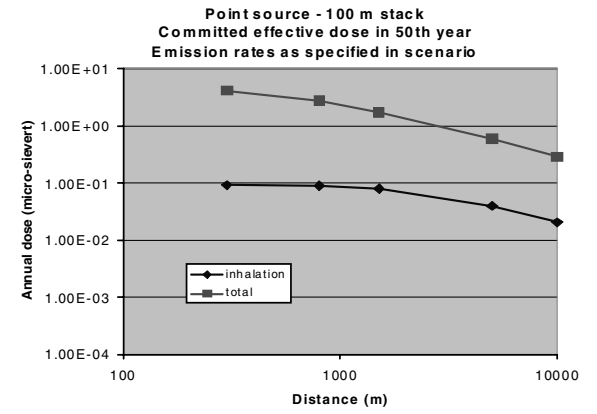

Figure 2. Hypothetical stack scenario - PCCREAM predictions.

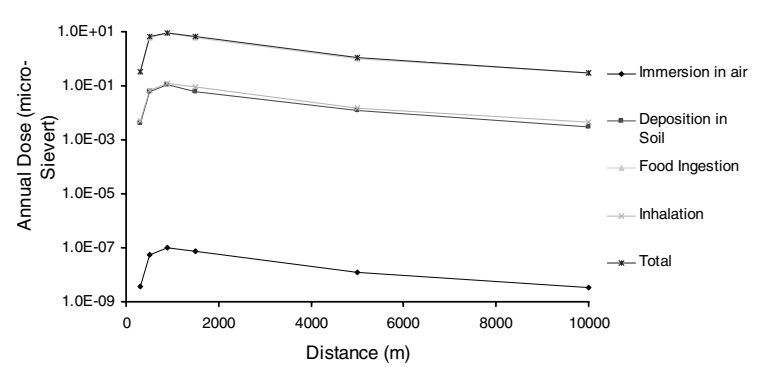

Figure 3. Hypothetical stack scenario - CROM predictions.

\subsection{Hypothetical area source}

Four models were used for testing the area source scenario. RESRAD-OFFSITE and DOSDIM + HYDRUS use different approaches for modelling groundwater flow and contaminant transport, but the predictions of both models were similar. The RESRAD-OFFSITE model was 'calibrated' by estimating the natural background dose level. Although RESRAD v6 and PRESTO are designed for on-site calculations, the results indicated that PRESTO is not particularly appropriate for this type of detailed calculation.

The general agreement between the DOSDIM and RESRAD results was good, considering the differences between the models. However, whereas DOSDIM + HYDRUS predicted that there would be no leaching of radionuclides from the waste if the waste was assumed to be clay, RESRAD did predict slow leaching.

The HYDRUS standard value of $230 \mathrm{~m} \mathrm{a}^{-1}\left(0.63 \mathrm{~m} \mathrm{~d}^{-1}\right)$ for the hydraulic conductivity of a mixture of $80 \%$ sand and $20 \%$ clay (taken from the HYDRUS Rosetta database) was used in the HYDRUS calculations, whereas RESRAD used the values specified in the scenario.

Soil-plant uptake factors were not specified in the original scenario description. Therefore assumptions had to be made for both models, in order to calculate doses resulting from ingestion of contaminated food. The scenario specifications were subsequently revised to include the soil-plant uptake factors. This scenario is much more complex than the point source scenario, in terms of specification and choice of input data. The importance of the leaching process and the ground water pathways when dealing with surface and near-surface disposal of waste means that there are many choices to be made by the user when setting up these packages to model this scenario. This was noted by the DOSDIM user, who pointed out several important omissions in the original scenario specifications, and by the 
RESRAD users, who had difficulty agreeing on the land use specifications for the calculations. The resolution of these difficulties led to two important conclusions:

1. it is not always possible to specify the scenario without going through an iterative process of testing and modification;

2. good communication between modellers is essential, to ensure that all modellers use the same site specifications and the same values for environmental parameters

RESRAD-OFFSITE was also used for testing the hypothetical area source + river scenario. Until predictions from other models are available, definitive conclusions cannot be drawn.

\subsection{Real scenario - lignite power station}

The lignite power station scenario was tested using PC-CREAM, COMPLY and CROM. Although the available meteorological data were not in a suitable form for use with PC-CREAM, and other assumptions had to be made to apply the model, the model predictions were in reasonable agreement with the measurement results.

Table 2. Predicted and reported deposition rates for the lignite power plant.

\begin{tabular}{|c|c|c|c|c|}
\hline & PC CREAM & & Measured & \\
\hline & $\begin{array}{c}{ }^{238} \mathrm{U} \\
\left(\mathrm{Bq} \mathrm{\textrm {m } ^ { - 2 }}\right)\end{array}$ & $\begin{array}{c}{ }^{232} \mathrm{Th} \\
\left(\mathrm{Bq} \mathrm{m}^{-2}\right)\end{array}$ & $\begin{array}{c}{ }^{238} \mathrm{U} \\
\left(\mathrm{Bq} \mathrm{m}^{-2}\right)\end{array}$ & $\begin{array}{c}{ }^{232} \mathrm{Th} \\
\left(\mathrm{Bq} \mathrm{m}^{-2}\right)\end{array}$ \\
\hline Plant A & $2.5-4.1$ & $0.12-0.19$ & & \\
\hline Plant B & $1.5-2.8$ & $0.07-0.14$ & & \\
\hline Total & $4.0-6.9$ & $0.19-0.33$ & $2.36-11.02$ & $0.19-1.20$ \\
\hline
\end{tabular}

The results presented in Table 2 show that there is extremely good agreement between the measured data and the predicted values from PC-CREAM.

Assumptions were made regarding the consumption rates and occupancy times/inhalation rates of the critical group. Calculated doses from the 'Sum of stacks' run show that the total dose over the first year is between 2.8 and $4.3 \mathrm{mSv}$ and integrated over a 50 year period is between 3.6 and $5.5 \mathrm{mSv}$. Most of this dose is calculated to be delivered through inhalation of ${ }^{226} \mathrm{Ra}$ and ${ }^{238} \mathrm{U}$.

The predicted total doses between COMPLY and PC-CREAM are very similar; COMPLY predicts a maximum effective dose of $2.4 \mathrm{mSv}$ (Figure 4) whereas PC-CREAM predicts a range of $2.8-4.3 \mathrm{mSv}$, depending on what receptor and what stack is being considered. CROM was applied to the scenario looking at the impact of ${ }^{238} \mathrm{U}$ only. Predicted deposition rates of ${ }^{238} \mathrm{U}$ varied between a factor of 2 to 4 higher than the reported deposition values. Further investigation is required to understand such differences.

\section{Effective Doses}

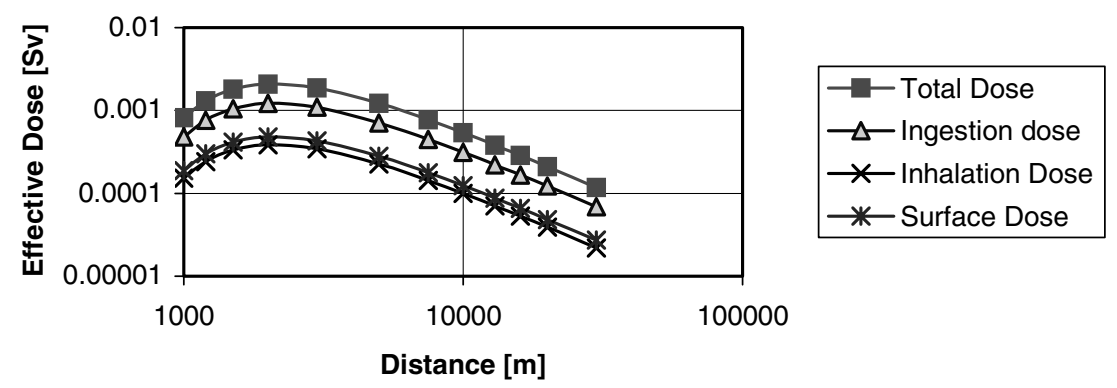

Figure 4. Doses as a function of distance, calculated using COMPLY. 
The work carried out during this program has resulted in the identification of several important issues that require consideration in the selection and utilization of computer models for NORM risk assessment. These issues cover suitability, selection, use and misuse of available models, as well as training and guidance for modelers, and acquisition of data for model inputs. In addition, a series of recommendations for future work have been made in [2], with particular emphasis on integration with other programs and needs.

\section{References}

[1] United States Environmental Protection Agency, Welsbach / General Gas Mantle Contamination Site, Camden, New Jersey: Remedial Investigation / Feasibility Study Report; Vol. I and Vol. II. Contract No. 68-W9-0051, January 1999.

[2] EMRAS: The NORM Working Group Final Report (in press)

[3] International Atomic Energy Agency, Safety Report Series No. 19. IAEA, Vienna, (2001).

[4] United States Environmental Protection Agency, EPA 520/189003. USEPA, (1989).

[5] United States Environmental Protection Agency, EPA 402-B-92-01. USEPA, (1992).

[6] A. Mayall, T. Cabianca, C. Attwood, C.A. Fayers, J.G. Smith, J. Penfold, D. Steadman, G. Martin, T.P. Morris, and J.R. Simmonds, 1997. European Communities Publication no. EUR 17791 EN, (1997).

[7] C. Yu, A.J. Zielen, J.-J. Cheng, D.J. LePoire, E. Gnanapragasam, S. Kamboj, J. Arnish, A. Wallo III, W.A. Williams, and H. Peterson, User's manual for RESRAD version 6. Environmental Assessment Division; Argonne National Laboratory, Argonne, Illinois 60439, (2001).

[8] Yu, C., E. Gnanapragasam, S. Biwer, S. Kamboj, J.-J. Cheng, T. Klett, D.J. LePoire, A.J. Zielen, S.Y. Chen, W.A. Williams, A. Wallo III, S. Domotor, T. Mo, and A. Schwartzman,. User's Manual for RESRAD-OFFSITE Version 2. Environmental Assessment and Information Sciences Division, Argonne National Laboratory, Argonne, Illinois, (2007).

[9] T. Zeevaert, http://www-ns.iaea.org/downloads/rw/projects/emras/norm/appendix 1-to-5thmeeting-report.pdf (2005).

[10] USEPA, http://www.epa.gov/radiation/assessment/presto.html (2007).

[11] D. Pérez Sanchéz, V. Koukouliou, and K. Kehagia, Characterization and modelling of naturally occurring radioactive material releases from a phosphogypsum disposal area in Greece. Presented at the NORM V conference, Seville, (2007). 